\title{
El pecado, la vergüenza y la culpa en el pensamiento védico (Estudios sobre el mal, la culpa y el pecado en el Ṛgeda y en el pensamiento brahmánico, I $)^{1}$
}

\author{
Francisco J. RUBIO ORECILLA \\ Unidad Asociada de Estudios Árabes y Orientales \\ Universidad de Zaragoza \\ rubio.orecilla@hotmail.com
}

\begin{abstract}
RESUMEN
A partir de los textos originales, especialmente el Rgveda, se someten a examen los conceptos de mal, culpa y pecado en la ideología védica y brahmánica. Para el pensamiento védico eran pecaminosas las infracciones contra el rtá, en concreto drúh: mentira, traición, faltar a la palabra dada. La ideología védica presenta rasgos de las «culturas de la vergüenza», en las que una mala acción no crea sentimientos de culpa personal, arrepentimiento o contrición, sino en primer lugar, temor a la pérdida de la estimación pública. Cuando se pide a los dioses quedar libre de las ataduras que son la consecuencia esperada de las malas acciones, no se hace distinción en los textos entre una mala acción intencionada, un error casual o inconsciente, ni entre pecados propios o ajenos, ya que también las consecuencias de un pecado ajeno, en forma de polución, pueden contaminar a terceros. El análisis de avadyá «vergüenza» se lleva a cabo en textos acerca del nacimiento de Indra (RV 4.18) y la muerte de Namuci (MS 4.3.4).
\end{abstract}

Palabras clave: hinduismo, brahmanismo, religión védica, filología védica, mal, culpa, pecado.

\section{Sin, shame, and guilt in the Vedic ideology (Studies on evil, guilt and sin in the Rgveda and in the Brahmanic ideology, I)}

\begin{abstract}
The concepts of evil, guilt and sin in the Vedic and Brahmanic ideology are here studied, starting from textual analysis, especially of the Rgveda. For the Vedic mind were sinful all infractions of r $r$ tá, specifically drúh: falsehood, betrayal and active breaking of a promise. The Vedic ideology shows so features of the «shame cultures», where an evil deed don't produce guilt feelings, remorse or contrition, but in first line, fear of losing the public respect. When the gods are beseeched to free men from the fastenings that are the expected outcome of an evil deed, there is any distinction made in the texts between deliberate misdeeds,
\end{abstract}

\footnotetext{
${ }^{1}$ Esta serie de trabajos constituye una profunda reelaboración de la conferencia que pronuncié en un encuentro de orientalistas españoles sobre el tema del mal, la culpa y el pecado que tuvo lugar en Salamanca en marzo del año 2000. Aquella investigación se realizó en el marco proyecto JCL-SA 58/98 Traducción integral comentada del Rg-Veda al español; esta revisión y reelaboración se está llevando a cabo gracias al Proyecto FFI2009-13058: Formas de la Épica Hispánica: Tradiciones y Contextos Históricos y a mi contratación como investigador ARAID del Gobierno de Arágon.
} 
a casual or unconscious mistake, nor between own or others' sins, for the consequences of alien misdeeds, in form of pollution, can too contaminate others. The analysis of avadyá «shame» is done on texts about Indra's birth (RV 4.18) and Namuci's death (MS 4.3.4).

Keywords: Hinduism, Brahmanism, Vedic religion, Vedic philology, evil, blame, shame, sin.

SUMARIO: 1. Introducción. 2. Sacrificio y verdad, microcosmos y macrocosmos. 3. Maldad e impiedad. 4. Falsía y vergüenza. 5. Los secretos vergonzosos de Indra: su nacimiento. 6. Indra y Namuci. 7. Lo vergonzoso y lo malo. 8. El vituperio y la culpa.

FECHA DE RECEPCIÓN: 27 DE 07 DE 2011 FECHA DE ACEPTACIÓN: 17 DE 11 DE 2011

\section{INTRODUCCIÓN}

El objeto de este trabajo es analizar las nociones de culpa y pecado y los términos que las expresan en el Rigveda (en adelante: RV), ${ }^{2}$ estableciendo las oportunas co-

\footnotetext{
${ }^{2}$ Las abreviaturas utilizadas son las siguientes: (1) textos védicos y ediciones empleadas: AV = Atharvaveda-samhitā (recensión de Śaunaka): (a) Atharva Veda Sanhita, ed. R. von Roth y W. D. Whitney, Berlin, 1856 (reimpr. Berlín, 1966); (b) ed. electrónica V. Petr - P. Vavroušek - J. Gippert, http://titus.uni-frankfurt.de/. MBh = Mahābhārata: critical edition, eds. V. S. Sukhtankar, S. K. Belvalkar et al., BORI, Pune, en la ed. electrónica de John Smith, http://bombay.indology.info/. MDhŚ = Mānava-dharma-śāstra: Manu-smriti with the Manubhāssya of Medhatithi, ed. Gañgānātha Jha, Calcuta 1932-1939 (reimpr. New Delhi 1992), en la ed. electrónica de M. Yano - Y. Ikari, http://gretil.sub.uni-goettingen.de/. MS = Maitrāyaṇi-Saṃhitāa: (a) Maitrāyaṇi-Saṃhitā, ed. L. von Schroeder, Leipzig, 1881-1886, reimpr. Wiesbaden 1970-1972. (b) Yajurvedīya-Maitrāyani-Samhitā, ed. S. Dāmodar, Bombay, 1941. $\mathrm{PBr}=$ Pañcaviṇśa-Brāmana: (a) Tāndya-Mahābrāhmaṇa belonging to the Sāma-veda with the commentary of Sāyanāāārya, ed. A. Chinnasvami Śastri, Benares, 1935. (b) ed. electrónica de M. Kümmel, A. Griffiths y M. Kobayashi, http://gretil.sub.uni-goettingen.de/. RV = Rg-veda-samhitā: (a) Die Hymnen des Rigveda, ed. Th. Aufrecht, Berlin, $2^{\mathrm{a}}$ ed. 1877, reimpr. Berlin, 1955; (b) Rig Veda. A metrically restored text, ed. B. A. Van Noten y G. B. Holland, Cambridge (Mass.), 1994; (c.) ed. electrónica de H. S. Ananthanaraya, J. Martínez García, A. Lubotsky y J. Gippert, http://titus.uni-frankfurt.de/. ŚBr.k. = Śatapatha-Brāhamṇa, recensión Kāṇva: The Śatapatha Brāhmaṇa in the Kānvīya recension, ed. W. Caland y R. Vira, Lahore, 1926-1939 (reimpr. Delhi, 1983). ŚBr.m. = Śatapatha-Brāhmaṇa, recensión Mādhyamindina: (a) The Çatapatha-Brâmana in the Mâdhyandina-Çâkhâ, ed. A. Weber, Berlin, 1849; ed. electrónica H.S. Ananthanarayana, J. R. Gardner y J. Gippert, http://titus.uni-frankfurt.de/. TS = Taittirīya-Samhitāa: (a) TaittirīyaSaṃhitā with Padapātha and commentaries of Bhațta Bhāskara Miśra and Sāyanāāārya, eds. N.S. Sontake y T.N. Dharmadhikari, Pune, 1970; (b) Die Taittirîya-Saṃhitâ, ed. A. Weber, Leipzig (Indische Studien 11-12), 1871-1872; (c) edición electrónica M. Fushimi-J. Gippert, http://titus.uni-frankfurt.de/. VS = Vājasaneyi-Samhitāa: (a.) The Vâjasaneyi-Samhitâ in the Madhyamdina adn the Kânva-Çâkhâ with the Commentary of Mahîdhara, ed. A. Weber, Berlin-London, 1852; (b) ed. electrónica de M. Kümmel-J. Gippert, http://titus.unifrankfurt.de/. (2) Gramáticas, diccionarios: AiGr. = Wackernagel, Jakob y Debrunner, Albert, Altindische Grammatik, Göttingen, Vandenhoeck \& Ruprecht, 1951-1964. EWAia = Mayrhofer, Manfred, Etymologisches Wörterbuch des Altindoarischen, Heidelberg, 1992-2001. Geldner, RVÜb. = Geldner, Karl Friedrich, Der Rig-Veda (aus dem Sanskrit ins Deutsche übersetzt und mit einem laufendem Kommentar versehen) Cambridge (Mass.), 1951. Grassmann, Wb. = Hermann Grassmann, Wörterbuch zum Rig-Veda, Wiesbaden, $1955^{3}$ (reimpr. de la $3^{\mathrm{a}}$ ed. de Leipzig, 1875). MW = M. Monier-Williams, Sanskrit-English dictionary, etymologically and philologically arranged with special reference to cognate Indo-European languages, Oxford, $1899^{2}$ (reimpr. New Delhi, 1988³). Oldenberg, Noten = Hermann Oldenberg, Rgveda. Textkritische und exegetische Noten,
} 
nexiones con su desarrollo en el brahmanismo posterior, pues una serie de conceptos centrales en la ideología de los primeros poetas védicos (ṛtá, bráhman, māyáa, dhî́, etc.), algunos de los cuales seguirán presentes de un modo u otro en el hinduismo postbúdico, varían y se transforman substancialmente ya en las colecciones védicas subsiguientes (Yajurveda, Sāmaveda, Atharvaveda), e incluso en el seno del propio RV. A la hora de manejar conceptos como «mal», «malvado» o «pecado» en culturas como la de los pueblos védicos, es evidente que no podemos extrapolar las connotaciones que tales términos despiertan en nosotros; por ejemplo, será muy difícil discernir entre «crimen» como atentado contra una ley civil, y «pecado», como acto que se opone a una norma religiosa, puesto que tales distinciones no existen, ni para la ideología védica ni, posteriormente, para la ideología del dharma.

Además, traducir por «pecado» una palabra dada en una cultura ajena a la nuestra es siempre problemático, pues éste es un término muy marcado para nosotros por la cultura judeo-cristiana y también por el sistema judicial romano-germánico, donde cada falta tiene su compensación, el individuo es culpable sólo del crimen cometido con intención, el castigo último por los pecados cometidos se produce después de la muerte, y el individuo sufre remordimientos y miedo al castigo en la vida eterna y también a las penas que la ley humana pueda imponerle en ésta. Desde luego, la intencionalidad «malvada» desempeña un papel relevante en nuestro concepto de culpa. Y al mismo tiempo, p. ej. en español la palabra «mal» puede referirse desde a algo «mal» hecho, sea cual sea el grado, incluyendo lo erróneo o roto, o referirse a la percepción de un dolor físico (p. ej., «estoy mal», «me hace mal la rodilla») -no es el caso de las lenguas germánicas, que disponen de varios términos (p. ej. ingl. «bad», «evil», al. «schlecht», «übel», «böse», «schlimm»-). La cuestión se complica si son varias palabras las que hay que traducir -en el caso del sánscrito védico, énas, ágas, kílbiṣa y, más tarde, pāpmán- que, según contextos, pueden responder a «falta», «crimen», «pecado» y «culpa»; esto teniendo en cuenta que, salvo excepciones, los himnos rigvédicos no están focalizados, como veremos, en la expiación o petición de perdón por faltas cometidas, y otros textos védicos, como los sūtra, atienden sólo a la expiación de acciones erróneas en el contexto litúrgico.

La noción de pecado en la literatura védica, tal y como se detalla en las descripciones del brahmanismo usuales, ${ }^{3}$ incluye los siguientes rasgos:

1909-1912, Berlin. PWb. = Petersburger Wörterbuch: O. Böhtlingk - R. von Roth, Sanskrit Wörterbuch herausgegeben von der Kaiserlichen Akademie der Wissenschaften (7 vols.), St. Petersburg, 1853-1895. Renou, $E V P=$ Renou, Louis, Études Védiques et Pāninéennes 1-17, París, 1956-1969.

${ }^{3}$ A. Bergaigne, La religion védique d'après les hymnes du Rig-Veda, vol. III, París 1883, pp. 150ss.; Oldenberg, Die Religion des Veda, Berlin, 1894, pp. 286-299; A. B. Keith, The religion and philosophy of the Veda and Upanishads, vol. I, Cambridge-London, 1925, pp. 245-249 y 264-268; L. Renou, Vedic India, Calcutta, 1957, p. 58, J. Gonda, Les religions de l'Inde, vol. I: Védisme et Hindouisme ancien, Paris, 1962 ( $1^{\text {a }}$ ed. alemana Stuttgart, 1960), pp. 53-56, 98-101, 106, W. Doniger O'Flaherty, The origins of evil in Hindu mythology, Berkeley - Los Angeles, 1976, p. 170, etc. Monografías específicas sobre el concepto de pecado y el mal en la India védica: H. Lefever, The Vedic idea of sin, Nagercoil, 1935; H. Hartog, Zur Frage des frühvedischen Sündenbegriffes. Eine sprach- und religionsgeschichtliche Untersuchung; Thesis Marburg, 1939; S. Rodhe, Deliver us from evil. Studies on the Vedic ideas on salvation, Lund, 1946. 
a) Existen acciones contrarias al ṛtá que provocan la cólera divina; principalmente, atentados contra la verdad: la traición al amigo o al aliado, la mentira, la calumnia. Son también reprobables la cicatería en las ofrendas a los dioses y la falta de generosidad para con los sacerdotes; en el brahmanismo postrigvédico tienen especial protagonismo como «pecado» los errores rituales, fortuitos. Junto a catálogos de vicios que suelen incluir el juego, la bebida y las mujeres (p.ej., RV 7.86.6), el brahmanismo establecerá además una compleja casuística de situaciones que implican impureza o inadecuación ritual. ${ }^{4}$

b) Los dioses, especialmente Varuna, vigilan las acciones de los hombres para castigar los actos contra el rtá, pero a su vez dioses centrales en el panteón, como Indra, pueden pecar, o ser impuros a efectos rituales, como los Aśvin.

c) Las mismas consecuencias se sufren por un pecado intencionado que por uno cometido de modo involuntario; en diversas ocasiones el orante suplica saber por qué se le está castigando, ya que no conoce cuál ha sido su error; igualmente, se pueden sufrir las consecuencias de pecados cometidos por otros.

d) Esas consecuencias se designan figurativamente como «ataduras» con que Varuṇa sujeta a quienes no acuden a él con sacrificios, para que los libere. Los $\bar{A}$ ditya, dioses del orden social con Varuna a la cabeza, reciben su nombre por ser hijos de la diosa Aditi, la «sin ( $a$-) atadura (diti-)». Estas ataduras pueden convertirse en enfermedades o desgracias que afectan inesperadamente al presunto pecador, sin que éste pueda discernir cual es la causa concreta de la ira de Varuna.

e) El pecado se considera como una deuda que se ha de saldar con sacrificios. También, y especialmente en el AV, es como una especie de sustancia que se adhiere como una enfermedad, de la que hay que purificarse mediante encantamientos. Las expiaciones rituales que se aplican para apartar el mal no hacen distinciones entre el mal causado por un pecado o infracción moral, por un error inconsciente o involuntario, o por un simple accidente.

f) El pecador no experimenta arrepentimiento o contrición; teme las consecuencias desagradables que para él pueda tener su mala acción (o una mala acción de otros), pero no expresa sentimientos como haber sido ingrato con los dioses, o de ser indigno del perdón.

De un modo u otro, para los europeos del s. XIX esto implicaba un carácter «primitivo», como también lo implica para los estudiosos hindúes que parten de su propio concepto de dharma y retribución kármica. ${ }^{5}$ Desde Max Müller en adelante, una

\footnotetext{
${ }^{4}$ Vid. H. W. Bodewitz, «Sins and vices: their enumerations and specifications in the Veda», IIJ 50 (2007) p. 317-339, tema sobre el que volveremos en la continuación de este trabajo.

${ }^{5}$ P. ej., A. B. Keith, op. cit., p. 266: «...to a primitive people, believing in the physical transfer of evil...»; para J. McKenzie, Hindu ethics: a historical and critical essay, Oxford, 1922, en el RV sólo podía haber un «sistema ético embrionario»: el ṛtá se identifica con la verdad, y poco más (pp. 8, 10); cfr. además H. G. Narahari, Atman in pre-upanișadic Vedic literature, Adyar-Chennai, 1944, p. 183: «From simple worshippers of the personified forces of Nature like the Vedic Aryans, it may not be possible to expect a theory of Virtue and Vice which is either elaborate or complicated.»
} 
corriente de estudiosos del hinduismo ha tendido a ver una cierta «degeneración»: los conceptos propiamente «éticos», tal y como se expresarían en los himnos rigvédicos a Varuna, habrían dejado paso a un concepto «materialista» del mal como un miasma físico que hay que limpiar mediante procedimientos rituales adecuados; otros en cambio entienden que hubo una evolución inversa desde el concepto de «polución» mecánica propio de los textos védicos hasta la idea del pecado como desobediencia a la ley moral (dharma) e incluso, en el hinduismo de la bhakti, como algo que la divinidad perdona; en realidad, desde el principio, coexistieron diferentes conceptos de pecado, y unos quedaron obsoletos y otros en parte se mezclaron, pese a documentarse por separado en textos diversos. ${ }^{6}$

Al margen de prejuicios, resulta claro que en el vedismo está presente desde el principio la idea de que las malas acciones tienen malas consecuencias, lo que es en sí un planteamiento ético, por más que se presuponga, p. ej., la existencia de un mal como polución de la que no se es responsable. Ciertamente, no se hace distinción entre liberarse del mal resultante de un pecado, de una maldición, de un accidente o de un error ritual $;{ }^{7}$ pero emplear un mismo término para el pecado cometido y para sus consecuencias (énas y ágas se solapan parcialmente, pāpá y pāpmán abarcan también ambos conceptos) no implica creer que todo mal que sobreviene se deba a un pecado previo. ${ }^{8} \mathrm{~A}$ la inversa, tanto el mal planeado contra alguien como el pecado cometido inconscientemente sí tienen como resultado un mal en forma de polución, que se ha de purificar mediante el rito. La ausencia de expresión de remordimiento en el RV puede deberse a que los himnos son textos que un poeta-sacerdote compone para un patrón que ha encargado esos versos para recitarlos en el marco de un ritual concreto con el que éste busca liberarse de las consecuencias de pecado: ni el autor ni su patrón están interesados en describir el pecado en sí, o en subrayar la implicación personal del culpable, y muchas veces las alusiones al pecado son exculpaciones cautelares de tipo más bien genérico. Raras veces habla el autor de sí mismo, p. ej. si pide ayuda contra las calumnias o acciones mágicas de rivales o enemigos, pero raras veces hace mención expresa de su propio comportamiento. ${ }^{9}$

Aquí es menester incidir en un aspecto de la cultura védica que pocas veces se pone de relieve, ya que los textos, compuestos por brahmanes y para brahmanes, nos escamotean de continuo el ámbito social más amplio en el que los himnos védicos tuvieron su función primitiva: el yajamāna, el señor que encarga un sacrificio dado, pertenece por antonomasia a la casta guerrera, casta en la que imperaba una ética de la vergüenza, antes que una ética de la culpa: importa más lo que dicen de uno que lo que uno haya hecho, excepto si uno ha de sufrir las consecuencias de modo directo; pero las repercusiones psicológicas (en forma de sentimientos de culpa, contrición, arrepenti-

\footnotetext{
${ }^{6}$ S. Rodhe, op. cit., p. 161; W. Doniger O'Flaherty, op. cit., p. 166.

${ }^{7}$ S. Rodhe, op. cit., p. 150.

${ }^{8}$ H. W. Bodewitz, «The Vedic concepts ágas and énas», IIJ 49 (2006) p. 228: ágas se asocia de modo más exclusivo con el pecado cometido que énas.

${ }^{9}$ Bodewitz, loc. cit. p. 235. Una notable excepción son ciertos himnos de Vasișțha a Varuṇa, que analizaremos en un segundo trabajo.
} 
miento...) quedan en un segundo plano, si es que no se relegan por completo. Dodds ${ }^{10}$ aplicó a la religión homérica el concepto de «cultura de la vergüenza», procedente de la antropología norteamericana: ${ }^{11}$ ante sus actos más descabellados o irracionales, los

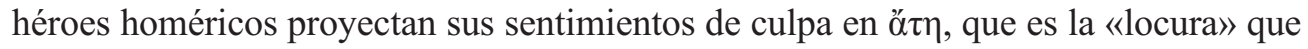
ponen en su espíritu fuerzas divinas inidentificables, y las acciones que realizan, antes

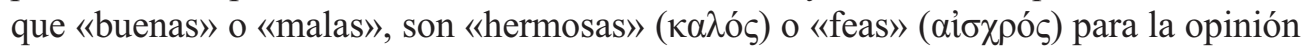
pública. Signo de ese predominio ideológico de la «vergüenza» en el mundo védico

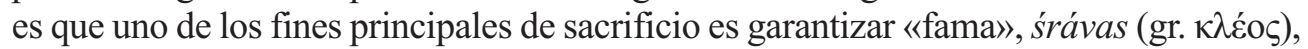
yáśas «prestigio». La falta de implicación personal en la culpa está vinculada a este modo de ver las cosas: si uno hace algo mal, le dará vergüenza la mala opinión que los demás puedan tener de él, pero no experimentará sensación personal de culpa, contrición, etc., lo que lleva a una desvinculación entre intención, mala acción y castigo. P. ej., en el brahmanismo postrigvédico, la sangre se considera como una fuente principal de impureza ritual; por lo tanto, la mala reputación recae automáticamente sobre todo aquel que ha derramado sangre, a margen de si se trata de un crimen premeditado, de un accidente, o incluso de sangre derramada en defensa propia: incluso Indra al matar a Vrtra se convierte en pecador $(\S 4, n .35)$, pese a que esa muerte y la subsiguiente liberación de las aguas constituyen el acto cosmogónico primordial de la mitología védica. Por todo ello, la calumnia causa verdadero temor, pues una falsa acusación atraerá en cualquier caso el desprecio de los dioses sobre el calumniado; sólo los brahmanes pueden mostrar (mostrar y no demostrar) que el verdadero pecador es el calumniador, mediante un sacrificio o ritual adecuado. Más adelante $(\S 4)$ profundizaremos sobre el concepto de avadyá «vergüenza, infamia».

\section{SACRIFICIO Y VERDAD, MICROCOSMOS Y MACROCOSMOS}

En los himnos del RV el hombre se sitúa ante los dioses en una posición de intercambio. En un principio, el sacrificio representaba un banquete al que asistían los dioses para comer y beber las ofrendas del fiel: ${ }^{12}$ por lo general, leche, miel, cereales, o soma, una bebida litúrgica, cuyo uso se remonta a época indoirania y que en la formación de la cultura védica acabará divinizada. Como retribución, las peticiones típicas que se dirigen a la divinidad son riqueza -en forma de caballos y, sobre todo, de ganado vacuno-, salud y fecundidad; más específicamente, hijos varones y lluvia,

${ }^{10}$ E.R., Dodds, The Greeks and the irrational, Berkeley-Los Angeles, 1951, citado por la trad. española: Los griegos y lo irracional, Madrid, 1980, pp. 30-31, 37, nn. 106, 109.

${ }^{11}$ En el clásico de Ruth Benedict The chrysanthemum and the sword, Cleveland, reimpr. 1967 (1 ${ }^{\mathrm{a}}$ ed. 1946) sobre la cultura japonesa; vid. esp. pp. 222-223 para la definición de «cultura de la culpa» (p. ej., la nuestra) como opuesta a una «cultura de la vergüenza» (de modo prototípico, la japonesa).

${ }^{12}$ No es posible recuperar el ritual rigvédico original. Muchos términos técnicos de la liturgia brahmánica aparecen en el RV, signo de que se había desarrollado un ritual muy complejo ya en la época de composición de los himnos; la presencia de sus correlatos en el mundo iranio ponen de manifiesto que tanto el ritual del soma como el del fuego, y una serie de funciones litúrgicas (*yajna-, *anću-, *m(a)nzd $d^{h} a H s-,{ }^{*} k r a t u-,{ }^{*} j^{h} a u t r a-;$ *atharuan-, *ućig-, *jhautar-, *kaunhai-) se remontan a época indo-irania. 
que trae fertilidad a los campos y los pastos, lo que a su vez sirve para mantener el ganado. A Indra se le pide sobre todo protección contra los enemigos en la guerra y ayuda para obtener la victoria. Y como las ofrendas por lo general se vierten en el fuego sacrificial, es Agni, el fuego sacrificial deificado, el encargado, como mensajero, de llevarlas en forma de humo hasta el cielo, donde habitan los dioses. Así se traza un círculo que vincula a poderes, sacerdotes y dioses en torno al rito y a las ofrendas sacrificiales. ${ }^{13} \mathrm{El}$ sacerdote védico en sus himnos elogia a los dioses; de ese modo, el sacerdote acrecienta el poder de los habitantes del cielo para que éstos puedan ayudar a los hombres: no sólo alimentándolos con libaciones y comida, sino mediante el poder vinculante y mágico de la palabra durante el sacrificio. El núcleo del poder religioso del sacrificio para los redactores del RV era el bráhman, la fórmula sacrificial correctamente enunciada o, mejor dicho, la «formulación», el acto de enunciar una fórmula dada y, sobre todo, la capacidad de disponer palabras según determinadas normas (versificación, estilo, léxico) generando mantra, fórmulas litúrgicas eficientes durante el sacrificio, en la medida en que contienen en sí la expresión de verdades no evidentes en sí mismas. ${ }^{14}$ Se establecía así una interacción entre el poder del sacerdote, capaz de atraer a los dioses con sus cantos, y los dioses mismos. El sacrificio se percibe como un microcosmos que no sólo reproduce el orden del macrocosmos, sino que lo sustenta: la leche vertida en el fuego sacrificial es la lluvia por la que se suplica, el zumbido de las piedras que trituran el grano de la ofrenda sacrificial es el trueno que anuncia el Monzón y es el mugido de las vacas fecundas.

La identidad total que el pensamiento védico atribuye a estas ecuaciones es r rtá; con frecuencia se traduce como «orden cósmico», pero su significado es más complejo: por su etimología significa «lo (mutuamente) encajado, lo adecuado»; su negación an-rrtá- no significa «caos» (como opuesto a «orden»), sino «mentira» y el correlato de r tá en iranio (persa ant. arta; avéstico aša) se traduce sin más por «verdad». El otro término sánscrito para «verdad» es satyá, que etimológicamente significa «lo que es, lo que existe», derivado de as «ser, existir», y se opone tanto a a-satyá- «irreal, falso» como a an-ṛtá- «mentira». En el mundo védico, ṛtá es propiamente la «verdad eficiente» que sustenta el orden cósmico,${ }^{15}$ una fuerza activa que se opo-

\footnotetext{
${ }^{13}$ Estas fuerzas de intercambio recíproco se basan en el concepto de rṇá, «deuda», la red de obligaciones mutuas que se establece con dioses, antepasados y los rṣi de pasado, cfr. Ch. Malamoud, «La théologie de la dette dans le Brahmanisme», Purușārtha 4 (1980) pp. 39-62; trad. inglesa: «The theory of debt in Brahmanism», Ch. Malamoud, Debt and debtors, Delhi, 1983, pp. 115-135.

${ }^{14}$ Cfr. J. Gonda, Notes on brahman, Utrecht, 1950 y P. Thieme, «Brahman», ZDMG 102 (1952) pp. 91129.

${ }^{15}$ Ciertemente, rtá no se puede traducir sin más por «verdad», pero discrepamos en esto de la posición de H. I. De Chelmicki, «Concepto de R.ta en el Ṛg Veda», 'Ilu 4 (1999) pp. 25-56, que insiste en «orden cósmico» como significado cardinal de rtá; cfr. al respecto J. Gonda, Les religions de l'Inde I: Védisme et Hindouisme ancien, Paris, 1962 (tr. francesa de la $1^{\text {a }}$ ed. Die Religionen Indiens, vol. I, Stuttgart, 1960), pp. 98100 e idem, «Some notes on the study of Ancient-Indian religious terminology», History of Religions 1 (1962) pp. 243-273, esp. pp. 252-257, donde matiza la tesis sostenida por H. Lüders, Varuṇa II : Varuna und das Rta, Göttingen, 1959 (rtá = «(Warheits)verwirklichung»); más recientemente, $c f r$. S. W. Jamison y M. Witzel, Vedic Hinduism, Harvard, 1992, pp. 27, 67-68 (www.people.fas.harvard.edu/ witzel/vedica.pdf); Th. Oberlies, Die Religion des Rgveda, Wien, 1998, vol. I, p. 346 (definido doblemente como «das durch Wort und
} 
ne a las acciones negativas de la traición y la falsía (drúh, cfr. infra $§ 6$ ); es la realización del cosmos -y no una mera descripción de su estado «ordenado»-, puesta en marcha por los hombres mediante el sacrificio y por los dioses mediante los vratá, sus inamovibles mandatos. Así, r tá implica que lo que suceda en el sacrificio ha de suceder, en consecuencia, en el cosmos externo; de un modo u otro, pertenece también a ese orden natural que los dioses tengan a bien obedecer a la magia de la palabra. Por ejemplo, típicas del brahmanismo posterior son las narraciones en las que una divinidad queda ligada por un voto a una obligación ridícula, o en las que un brahmán o un demonio, por el hecho de haber llevado a cabo rituales correctos - que la tradición posterior sustituirá por ascesis yóguica-, obtiene poderes superiores a los de los mismos dioses, que quedan en inferioridad por desconocer las fórmulas y procedimientos rituales adecuados. En resumen, la formulación correcta de la palabra sagrada (bráhman) por un brahmán (brāhmaṇá), en un entorno ritual preciso (yajñá, el sacrificio) es, pues, la que mantiene y configura el ritá que, a su vez, sustenta el universo, incluidos los dioses. La ética rigvédica se sustenta en la adecuación de la conducta al rtá: el cumplimiento de los deberes religiosos -sacrificar según las costumbres de los arios y sin cometer error alguno-, y en seguir unas determinadas normas de conducta -mantener el orden social y, por encima de todo, respetar la palabra dada- ${ }^{16}$

\section{MALDAD E IMPIEDAD}

«Mal» $\mathrm{y}$ «malo» en indio antiguo se dicen pāpmán (n.), pāpá (adj. y n.), que en principio se oponen a bhadrá «bueno» en general, «beneficioso, positivo», no a vásu, «bien, lo bueno», propiamente «bienes, posesiones». En el ŚBr., pāpmán se opone también a śrì ${ }^{17}$ término complejo cuya semántica va más allá de su primer significado, «prosperidad, ventura», ya que, por ejemplo, śrí se pone en paridad con el bienestar en general (bhadrá, svastí), y, específicamente, con yáśas «honor, gloria, dignidad» y kìrtí «(re)nombre, (buena) fama». En los Brāhmaṇa, pāpá significa, además de «malo» en general, el mal cometido por uno; en cambio, pāpmán es el mal del que uno se quiere librar mediante las correspondientes acciones rituales (consecuencia por lo general de un error ritual, puesto que los Brāhmaṇa tratan de liturgia, precisamente); por eso, pāpmán no aparece como objeto de $k r$ «hacer», ni en contraste con púnya «bueno, puro», y sí en aposición a otros términos negativos, como Nírṛti «corrupción, destrucción» o mrtyú «muerte». ${ }^{18}$ En las Saṃhitā, como es de esperar, se preservan

\footnotetext{
Tat Gefügte (= die Wahrheit)», y como «überpersönliche Gesetzmäßigkeit der Weltordnung», con amplia bibliografía). En todo caso, en ṛtá la idea de «orden cósmico» se subordina a la noción de «poder creativo de la verdad eficiente», y está vinculado a la expresión mental o específicamente verbal de esas ecuaciones «verdaderas».

${ }^{16}$ M. Bloomfield, The religion of the Veda, the ancient religion of India, New York - London, 1908, p. 126.

${ }^{17} \mathrm{Al}$ respecto, J. Gonda, Aspects of early Viṣnuism, Delhi-Patna, 1969², p. 186; sobre el comparativo śreyas opuesto a papiyas, H. Rau, Staat und Gesellschaft im alten Indien, Wiesbaden, 1957, pp. 32-34.

${ }^{18}$ H. W. Bodewitz, Jaiminīya Brāhmaṇa I, 1-65: Translation and commentary, Leiden, 1973, pp. 39-40, n. 7 y pp. $40-41$, n. 9.
} 
otros términos más arcaicos (énas, ágas, kílbiṣa), cuyo significado es difícil de dilucidar pues habían caído ya en desuso en fechas tempranas.

El creyente védico pide constantemente ayuda a los dioses contra el mal, personificado o no en demonios (rákșas), o que destruya a los malvados. Entre los peligros externos que amenazan la existencia del ario védico se cuentan, desde luego, los enemigos de otras etnias, en la guerra o en la paz, los dásyu, los aborígenes (cfr. persa antiguo dahiyav- «país»), y los dāsá, los enemigos que eventualmente se toman como esclavos; ése será el significado de dāsá en la literatura más tardía. ${ }^{19}$ No queda excluido que entre ellos hubiese arios aculturados, traidores a sus dioses, o que simplemente no practicaban exactamente el mismo tipo de religión ārya aceptada y codificada como tal por los brahmanes del Pañjāb y el Kurukșetra, y más tarde extendida a todo el Âryavarta. ${ }^{20}$ Está claro que se considera pecaminoso el incumplimiento de los deberes religiosos: el peor malvado es el que no practica el sacrificio a los dioses como lo hacen los arios. Dignos del mayor desprecio son los que no adoran a los dioses (á-deva, ádevayu, ádevayat, etc.), los dásyu que inclumplen los mandatos de los dioses (avratá, apavratá), los que no ofrecen oblaciones (ásunvant, árarus); ocasionalmente se menciona a los adoradores del falo (śiśnádeva) o adoradores de «dioses estúpidos» (múrradeva). La equiparación de pecado (énas) y los dásyu está clara en textos como el siguiente:

\section{RV 2.12.10 \\ yáh śáśvato máhy éno dádhānān ámanyamānāñ chárvā jaghā́na | yáh śárdhate nấnudádāti șr hhyā́m yó dásyor hantā́ sá janāsa índrah $\|$ \\ Quien con su proyectil mató a muchos que, inconscientes, causaron gran énas ${ }^{21}$, quien no cede ante el arrogante en arrogancia, quien mata al dásyu: ¡ése, gentes, es Indra!}

El proceso de demonización de los enemigos bárbaros está muy avanzado ya en los textos rigvédicos, y de hecho todos los diccionarios (Grassmann, PWb., MW ssvv.) admiten como significado secundario para dāsá / dásyu el de «demonio»; se incide una y otra vez en que los bárbaros no sacrifican a los dioses védicos. Pero también son más dañinos para la comunidad los arios que no ofrecen sacrificios, o que no lo hacen con bastante generosidad: infringen el ṛtá y ofenden a Varuna; constituyen un peligro tanto para el fiel que ofrece sacrificios, que puede verse traicionado, como para la comunidad en su conjunto, ya que los infractores pueden atraer la desdicha, que no necesariamente recae sobre quien comete la infracción sino sobre quien está en

\footnotetext{
${ }^{19}$ Para una etimología de dāsá, dásyu en conexión con $\delta \tilde{\eta} \mu \circ \varsigma$, A. Lubotsky, «Reflexes of intervocalic laryngeals in Sanskrit», Kuryłowicz memorial, vol. I, ed. W. Smoczyński, Kraków, 1995, p. 231, n. 18; el i.a. dāsáremite al etnónimo iranio dāha recogido en las fuentes clásicas (lat. dahae, gr. ó́ot).

${ }^{20}$ M. Witzel, «Rigvedic history: poets, chieftains and politics», The Indo-Arians of ancient South-Asia: Language, material culture and ethnicity, ed. G. Erdosy, Berlin-New York, 1995, pp. 307-352; idem, «The development of the Vedic canon and its schools: The social and political milieu», Inside the texts, beyond the texts. New approaches to the study of the Vedas, Cambridge Mass., 1997, pp. 257-345.

${ }_{21}$ «Pecado»/«culpa»; en un segundo trabajo analizaremos los matices de énas, ágas, que precisamente por ello dejamos sin traducir aquí.
} 
contacto de un modo u otro con la misma. Contra ellos se suele pedir la protección del mismo dios Indra que, beligerante, extermina a los enemigos; también acude a Agni para que purifique con sus llamas la mancha ritual que implican tales conductas: tápo șv àgne ántarāmamátrān, tápa śámsam árarușah párasya «iQuema bien, Agni, a los enemigos de dentro, quema la proclama del de fuera que no hace ofrendas!» (RV 3.18.2ab); obsérvese cómo se centra el temor en la «proclama» (śámsa), en el reto o censura pública del enemigo. Más expresivo es todavía RV 7.6.3:

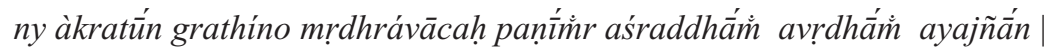

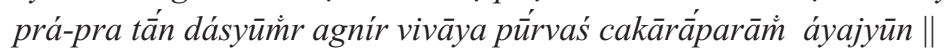

A los Pani ${ }^{22} \sin$ fuerza espiritual, nudosos ${ }^{23}$, injuriosos, sin fe, que no veneran, que no hacen sacrificios, adelante, adelante ha perseguido Agni a esos dásyu; el primero ha hecho ser últimos a quienes no sacrifican.

De nuevo, junto al carácter cicatero y ateo de los Paṇi se pone de relieve el temor del fiel ante las injurias que de él puedan decir sus enemigos ( $m r d h r a ́$-vāc- lit. «de palabras injuriosas»). Por su parte, Indra es también un dios que protege al fiel de los que cometen pecados: en RV 10.27.1 habla Indra en primera persona:

ásat sú me jaritah sấbhivegó yát sunvaté yájamānāya śíkșam | ánāsisirrdām ahám asmi prahantà satyadhṿ̛́tam vịjināyántam ābhúm \|

Sea mi afán, cantor, servir de ayuda al que me ofrece sacrificios exprimiendo soma; yo soy el exterminador del que no presenta ofrendas, del que trastoca la verdad (satya), del intrigante, del escaso.

\section{FALSÍA Y VERGÜENZA}

En estos textos se mencionan las infracciones que más repugnan al pensamiento védico más primitivo: la mentira, la calumnia, el faltar a la palabra dada o comportarse de modo torticero, la falta de generosidad, el no participar en los sacrificios. Si rtá es la verdad eficiente que establece el orden social y cósmico, drúh (relacionado etimológicamente con al. mod. Trug) es la mentira en acción que quebranta ese orden:

\footnotetext{
${ }^{22} \mathrm{Al}$ parecer los paṇis fueron en origen una etnia no védica, que algunos autores identifican con un grupo iranio conocido por fuentes griegas como Пápvor, vid. M. Witzel, 1995 (citado en n. 20), p. 321-. Pero en todo caso, en el RV, como demonios opuestos al poder de los dioses, participan en un episodio muy importante en la mitología védica, el rescate de las vacas que los paṇis habían escondido en la caverna Vala, que lleva a cabo Indra junto con la perra Saramā, los Añgiras - un grupo de sacerdotes míticos-, y Bṛhaspati -el dios-sacerdote, la encarnación de la palabra sagrada-.

${ }^{23}$ Lit. «nudosos, anudados»; Grassmann, $W b$., p. 416: «llenos de nudos, retorcidos», etc., esto es: «intrigantes»; Geldner RÜb. II, p.186, n. ad loc. da dos alternativas: o «que anudan [sus tesoros]» (es decir, tacaños con las ofrendas sacrificiales), o «que se anudan, encierran [en sus fortalezas]», es decir, los enemigos no arios (que, supuestamente, vivían ya en ciudades). Para una actualización sobre el final de la cultura del Indo, cfr. Witzel, Das alte Indien, München, 2003, pp. 21ss.
} 
la «traición», el romper la palabra dada, el «perjurio». Esta oposición entre ṛtá y drúh ${ }^{24}$ se remonta a época indoirania y en la ideología irania se constituirá en uno de los ejes de la religión. En el mundo védico es frecuente pedir a dioses como Indra o Agni protección contra los que cometen drúh: máa no mártāa abhí druhan tanūnām indra girvanah « «No cometan los mortales felonía contra nosotros, Indra deseoso de cantos!» (RV 1.5.10 ab), o también:
RV 4.4.15
ayấ te agne samídhā vidhema práti stómam śasyámānam grbhāya|
dáhāśáso raksásah pāhí asmā́n druhó nidó mitramaho avady át \|
Con esta leña, Agni, te vamos a honrar; toma a cambio el elogio anunciado. ¡Que- ma, guárdanos del monstruo innombrable ${ }^{25}$, de la traición (drúh), del reproche, de lo vergonzoso, oh tú, grande como Mitra!

Como ya se ha mencionado en $\S 1$, la ideología védica en su forma más arcaica presenta rasgos de las llamadas «culturas de la vergüenza». En ellas, la comisión de un delito no provoca un sentimiento personal de culpa, sino de extremo temor a perder la estima pública. De hecho, no hay una ética estipulada acerca de lo que es bueno o malo en términos absolutos. Así, Indra no sólo defiende a sus fieles castigando a los ateos, malvados y perjuros que violan las leyes de los arios: Indra defiende a cualquier ario que le sacrifique de cualquier enemigo, al margen de consideraciones éticas; si dos enemigos arios sacrifican a Indra antes de la batalla, obtendrá la ayuda del dios el que primero o con mayor generosidad lo haya hecho. En el mundo védico lo vergonzoso o censurable es avadyá, «lo que no debe decirse», esto es, «vergüenza, deshonor». ${ }^{26}$ Este concepto aparece entre las amenazas que los dioses han de mantener lejos del fiel, junto a ideas como drúh «felonía, traición» y níd «reproche» (como en RV 4.4.15, citado más arriba; $c$ fr. infra RV 5.53.14) En RV 6.15.12 (idéntico a RV 7.4.9) se pide a Agni protección contra el vanusyant, el envidioso, y contra lo avadyá:

\section{tvám agne vanușyató ní pāhi tvám u naḥ sahasāvann avadyā́t | sám tvā dhvasmanvád abhí etu pàthah sám rayí sprhayāyyah sahasrí $\|$ Tú, Agni, guárdanos del envidioso; tú, dominante, de lo vergonzoso; que acuda a ti, a tu redil †libre de calumnia, ${ }^{27}$ la deseable riqueza de mil.}

\footnotetext{
${ }^{24}$ H. Lüders, op. cit., pp. 415-420.

${ }^{25} A$-śás- «detestable, odioso»; aquí doy una traducción etimológica (-śas- de śamss), pues se pide protección contra avadyá; cfr. S. Scarlatta, Die Wurzelkomposita im Rg-Veda; Wiesbaden, 1999, p. 529.

${ }^{26}$ De $v a d^{i}$ "hablar, decir», mejor que de vand «elogiar»; vand carece de grado cero, cfr. pp. vanditá-, gerundivo vandya-. Si hay una relación entre ambas raíces (EWAia, vol. II, p. 503: vand ${ }^{i}$ de $v^{2} d^{i}$ mediante infijo nasal), entonces el carácter seț de ambas raíces ha de ser secundario (si no, la infijación sería $* u a d H \rightarrow * u(a) d$ $n a-H->* * v a n n \bar{a}-,{ }^{*}$ unnā- y no *ua-n-dH-); cfr. pāli vandati, prac. vamidä «saludar, honrar»); hay que contar con la influencia semántica y formal de nandati «alegrarse».

${ }^{27}$ Los dos últimos pāda no están claros, $c f r$. Geldner, RVÜb. II, p. 108, n. ad loc., «nicht klar». Pä́thas es difícil; en origen, quizá: «refugio, resguardo de las posesiones», vid. EWAia, vol. II, p. 119); aquí he optado por «redil». Dhvasmanvát- se puede traducir por «encubridor, calumniador», cfr. EWAia, vol. I, p.
} 
Así pues, avadyá aparece frecuentemente unido a las ideas de mentira, pública reprimenda y traición; en el siguiente pasaje, en cambio, se vincula la vergüenza al pecado de cicatería en la ofrendas:

\author{
RV 10.107.3 \\ daivī pūrtír dákșinā devayajyā́ ná kavāríbhyo nahi té prnánti \\ áthā náraḥ práyatadakṣināso avadyabhiyā bahávah prṇanti $\|$ \\ La dádiva ritual es ofrenda divina, sacrificio a los dioses; no [les sirve] a los taca- \\ ños, pues no hacen ofrendas. \\ Así, los guerreros al presentar la dádiva, muchos la ofrecen por miedo a la vergüenza.
}

Expresamente se dice que hay miedo a la mala opinión que una ofrenda poco generosa suscitaría. Es frecuente que avadyá (o su negación, anavadyá) aparezca junto a derivados de la raíz śams «hacer pública y solemne proclamación», bien por contraposición, bien en paralelo, p. ej. RV 1.93.5cd: yuvám síndhüṁr abhiśaster avadyấd ágnīṣomāv ámuñcatam grbhìtấn: «Vosotros dos las corrientes [de soma] que estaban sujetas las soltasteis, Agni y Soma, de la calumnia (abhiśasti) y la vergüenza», y también RV 1.167.8ab (avadyá...ápraśasta) y RV 10.99.5ab (áśastavāra...āréavadya). Además, como en RV 1.93.5, también en RV 3.31.8d sákhā sákhìmr amuñcan nír avadyāt se pide ser desatado del avadyá, terminología que es usual al hablar del pecado: Varuna debe «desatar» al pecador de las ataduras que representan las consecuencias funestas de su mala acción. La idea subyacente es un gran temor a la falsa acusación que, cierta o no, causará la vergüenza, la deshonra pública, que solo un ritual determinado puede eliminar:

TS 2.1.10.19-20

vāyavyàm gomrgám à labheta yám ájaghnivāmsam abhiśámseyuh |ápūtā vā etám vấg ṛchati yám ájaghnivāmsam abhiśamsanti

Que ofrezca un gayal (bos gavaeus) a Vāyu aquel a quien calumnien (abhi-śams) sin haber matado; en verdad, la palabra impura (ápūtā vấk) ${ }^{28}$ va a éste, a quien calumnian sin haber matado.

\footnotetext{
799 y L. Renou, EVP 4 (1958) p. 32: dhvasmán- «mancha que deja el humo, entendida a un tiempo como mancha física y moral»; idem, EVP 10 (1960) p. 75: dhvasmanvát- «el que oscurece la verdad con sus palabras». Para este pasaje L. Renou, EVP 13 (1964) p. 47 toma dhvasmanvád literalmente: «pacage doué de (fumée-) enténébrante»; pero ¿qué sentido tiene esa traducción? Idéntico problema se plantea H. Oldenberg, «Vedische Studien», ZDMG 54 (1900) p. 606, n. 1 «was voll Verfallenheit ist?». Mi traducción se basa en la enmienda de Ludwig que recoge Geldner loc. cit.: tvā' dhvas o esto es, a-dhvasmanvád, «carente de calumnia», en línea con las peticiones de los pāda ab. H. Oldenberg, Noten I, p. 376, rechazó esta enmienda, entendiendo que un compuesto con $a$ - privativa habría de ser karmadhāraya, con retrotracción del acento ( $* \dot{a}$ - $d h v^{o}$ ); pero quizá se podría entender como derivado en vat de *a-dhvasmán «no-oscuridad, no calumnia».

${ }^{28}$ Esto es, «mala reputación», vid. H. W. Bodewitz op. cit. supra en n. 18, p. 49 n. 18 sobre āślilā vāc, pāpivāc en $\mathrm{JBr}$ y $\mathrm{PBr}$.
} 


\section{LOS SECRETOS VERGONZOSOS DE INDRA: SU NACIMIENTO}

Por otro lado, se puede pedir a los dioses que mantengan en secreto lo que no debe decirse, lo vergonzoso, como en RV 1.34.3 donde se dice de los Aśvin que son avadya-gohana, «ocultadores de lo vergonzoso». A veces se contrapone la luz a lo avadyá, como en RV 2.19.5:

sá sunvatá indrah sūryam á devó rinan mártyāya stavān á yád rayím guhádavadyam asmai bhárad ámíśam ná étaśo daśasyán || 5 ||

Él, Indra, para el mortal que le exprime [soma], el dios alabado, hizo venir al sol, cuando Etaśa le trajo la riqueza que esconde lo vergonzoso, como parte [que le corresponde], honrándole.

El texto alude a un mito que solo conocemos por alusiones indirectas: Etaśa, un corcel mítico, llega a convertirse en caballo principal del tiro del carro de Sūrya, el sol, porque Indra hace trampa («lo vergonzoso»), y le ayuda a ganar una carrera (-el premio sería la «riqueza»-). ${ }^{29}$

El tema de esconder lo vergonzoso se vincula en ocasiones a Indra, ya que algunas de sus hazañas, además de ser violentas, tienen un componente artero que implica adentrarse en zonas grises desde el punto de vista ético. Por ejemplo, de avadyá se califica el nacimiento de Indra en RV 4.18:

avadyám iva mányamānā gúhākar indram mātấ vīryènā nỵ̛̣̦țam |

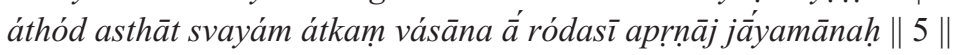

5. Como si le diese vergüenza, en secreto ocultó la madre a Indra, lleno de poder viril; entonces púsose al punto en pie y él mismo se vistió: llenó ambos mundos al nacer.

etấarșanti alalābhávantīr ṛtấvarīr iva saṃkróśamānāh $\mid$ etấ ví pṛcha kím idám bhananti kám ápo ádrim paridhím rujanti $\|6\|$ kím u șvid asmai nivído bhananta indrasyāvadyám didhișanta ápah $\mid$ mámaitā́n putró mahatā́ vadhéna vṛtrám jaghanvắm asṭjad ví síndhūn $\|7\|$ [Habla la madre:]

6.--Ellas ${ }^{30}$ corren haciendo alalá, alzando como veraces su voz: pregúntales qué dicen, qué montaña en torno suyo ${ }^{31}$ rompieron las aguas.

7. ¿Por qué pues le dirigen invocaciones? Las aguas quieren tomar sobre sí la vergüenza de Indra: ¡Mi hijo con su arma grandiosa al matar a Vṛtra soltó los ríos!

29 Vid. H. Oldenberg, 1894, Die Religion des Veda, Berlin, p. 170 y Th. Oberlies, Die Religion des Rgveda, Wien, 1998, vol. I, p. 224, n. 355. Al «esconder lo vergonzoso» de Indra gracias a su victoria en la carrera, Etaśa «honra» a Indra; daśasyá-, «honrar», es un denominativo derivado de *daśas, cognado de latín decus.

30 «Ellas»: las aguas primordiales, o las que ocultaron a Indra, vid. infra.

${ }^{31}$ Esto es, la montaña en la que estaban aprisionadas por obra de Vṛtra. 
En 5 avadyá se refiere a la vergüenza de la madre ${ }^{32}$ por el extraño nacimiento de Indra, distinto del modo de nacer de los otros dioses: según RV 4.18.1-4, el embarazo duró mil meses, y la madre se vio obligada a ocultarlo; finalmente Indra nace por el costado de la madre, pero ya adulto y con todos sus poderes (estrofa 5; cfr. RV 3.48.1, 3: Indra reclamó soma nada más nacer, despreciando la leche materna). Las aguas se alegran (6), pues Indra va a liberarlas de su encierro -el nacimiento de Indra con la ruptura del costado materno prefigura la ulterior liberación de las aguas encerradas en el vientre de la montaña, cuya ladera Indra rompe con su maza tras matar a Vṛtra-. En 7, de manera muy singular, las aguas, no se limitan a invocarlo con júbilo (bhananti, bhanante), ${ }^{33}$ sino que quieren tomar sobre sí (didhișanta) la vergüenza (avadyám): de nuevo, las fuerzas de la mentira que avergüenza se oponen al ṛtá (ṛtăvarī en 6, «veraces») que proclaman las aguas, gritando juntas (sam-kruś). ${ }^{34}$ Aunque es posible pensar que, de antemano, las aguas estén aceptando sobre sí la culpa de la muerte de Vṛtra, ${ }^{35}$ desde el punto de vista narrativo sería más lineal aceptar que, simplemente, las aguas toman sobre sí la vergüenza que se ha mencionado previamente en $5 .{ }^{36}$ Pero la linealidad narrativa no es precisamente una de las características de los himnos védicos: en la estrofa 8 de RV 4.18, su madre nos dice que se vio obligada a ocultarlo y abandonarlo después del parto, al parecer en las aguas del río Kuṣavā, y más adelante, se menciona que Indra mató a su propio padre (12):

mámac caná tvā yuvatíh parāsa, mámac caná tvā kusávā jagā́ra | mámac cid ápah śíśave mamrdyur mámac cid indrah sáhasód atiș̣that || 8 ||

8. [Sigue la madre:] -Ni por mí, de jovencita, te abandoné, ni por mí te tragó el Kușavā; por mí se habrían apiadado del bebé las aguas, por mí de golpe Indra se puso en pie.

kás te mātáram vidhávām acakrac chayúm kás tvā́m ajighāmsac cárantam |

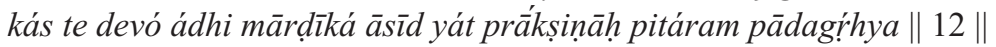

12. [narrador:] ¿Quién hizo viuda a tu madre? ¿quien te quiso matar, acostado o en movimiento? ¿Qué dios se apiadó de ti cuando aniquilaste a tu padre, tras cogerle por el pie? ${ }^{37}$

\footnotetext{
${ }^{32}$ Se menciona como madre de Indra a Aditi; Śavasī, de quien se dice también a veces que es hijo, no es sino una personificación de su poder (śávas). Hay que suponer que en la versión más antigua del mito, Indra es hijo del Padre Cielo, Dyaus Pitar (RV 4.17.4) y Tierra, Prthivī, vid. esp. W. N. Brown, «The creation myth of the Rig-Veda», JAOS 62 (1942), pp. 93-95.

${ }^{33}$ Las nivíd del ritual son un tipo de invocación litúrgica intercalada en un śastra «declamación» del hotar con la que se invita a los dioses al sacrificio, enunciando sus títulos y hazañas.

${ }^{34}$ El epíteto retávarī se predica en otros pasajes de Ușas, la Aurora; vid. § 8, n. 63 sobre la identificación de la salida del sol con la liberación del pecado.

35 Así p. ej. Geldner, $R V \ddot{U} b$. I, p. 442 (siguiendo a Sāyaṇa). La tradición yajurvédica considera unánimemente la muerte de Vrtra un pecado. En TS 2.5.1-2 la muerte del tricéfalo Viśvarūpa, hijo del dios Tvaștar, se considera un brahmanicidio (brahmahatya), y Tvașțar crea a Vṛtra para vengarse de Indra. En MS 4.3.4, como prólogo al mito de Indra y Namuci (infra § 6), al matar a Vṛtra Indra quebranta también un pacto de no agresión que había establecido con el asura.

${ }^{36}$ Para esta interpretación, H. Lüders, op. cit., pp. 551-552.

${ }^{37}$ Indra finge sumisión y luego mata a su padre.
} 
A esto se añade que, como preparación para su primera hazaña, la muerte de Vṛtra y la subsiguiente liberación de las aguas, sabemos que Indra robó su primer trago de soma en casa de Tvașțar, el dios artesano (cfr. RV 3.48.4). ${ }^{38}$ Así pues, los candidatos al avadyá que toman sobre sí las aguas en la estrofa 7 son muchos, puesto que son las mismas aguas que, veraces como testigos, aceptan la culpa de Indra, las que ocultan a Indra de los otros dioses tras una fechoría cometida tras nacer y previa a la muerte de Vrtra: bien la muerte de su padre, bien el robo de soma. Dado que en 6 las aguas declaran a gritos el ṛtá, no parece lógico que la vergüenza que toman sobre sí sea precisamente el nacimiento de Indra, esto es, contrario al rtá, aunque ni eso puede ser excluido a ciencia cierta. El hecho de que avadyá es «lo que ha de ser silenciado» obliga a la reticencia del poeta.

\section{INDRA Y NAMUCI}

En este contexto hay que entender un mito como el de la lucha de Indra y el asura Namuci, un episodio de la eterna guerra entre los deva, los dioses celestiales, y los asura,${ }^{39}$ seres divinos caracterizados por la $m \bar{a} y \bar{a}$, un poder mágico de «ficción», de engañar mediante la magia haciendo que unas cosas sean otras. En una de las versiones más arcaicas, la leyenda presenta la siguiente formulación: ${ }^{40}$

MS 4.3.4

(...) devấś ca vấ ásurāśs ca sámayatanta $|(\ldots)|$ indro vái námucim nălabhata $\mid$ sá raś-

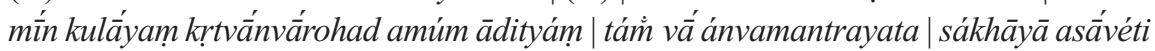
| sò 'bravīn | nấháṁ hanișyấmî̀ti | sò 'bravīt | samdhấm te sámdadhai yáthā tvā ná

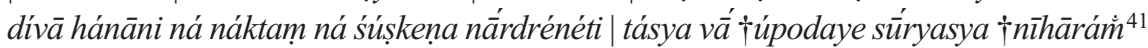
saṃtátyāpắm phénena śíro 'chinat $\mid$ tád vā enam ánvavartata $\mid$ mitradrúg asî́ti $\mid$ pāp-

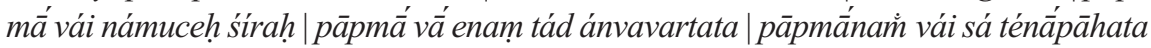

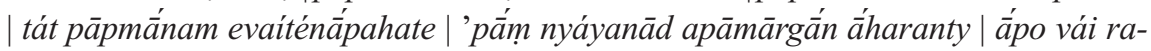
kṣoghnìr | apó rákșamssi ná taranti rákșasām ápahatyai | váro dákșināa | várenaivá váram̉ sprṇoty $\mid \bar{a}$ tmā́ hí vára $\mid \bar{a}$ tmấnam̀ hi tásya tád anvávartata $\mid$ yé devā́h purahsádo agnínetrā rakșohánas té no 'vantu | té nah pāntu | tébhyah svăhéty (...) ||

\footnotetext{
${ }^{38}$ Sobre la muerte del padre de Indra y el robo de soma, vid. Th. Oberlies, «Pūṣans Zahnlücken und Hermes' Vorliebe für Backwerk: Ererbte Strukturen des Pantheons der ṛvedischen Religion», Indoarisch, Iranisch und die Indogermanistik. Arbeitstagung der Indogermanischen Gesellschaft, 2.-5. Oktober 1997 in Erlangen, eds. B. Forssman y R. Plath,Wiesbaden, 2000, pp. 375ss., esp. p. 378.

${ }^{39}$ Es usual traducir asura por «demonio». En el brahmanismo la oposición original entre devas y asuras por la primacía en el sacrificio se reinterpretó como lucha entre «dioses» (que sacrifican con soma) y «demonios» (que engañan para obtener el soma). Pero en la religión aria más primitiva la oposición no era sistemática, y no se trataba de enfrentamiento nítido entre dioses «buenos» y demonios «malos» (como en el hinduismo postbúdico); el dios Varuna es, de hecho, un asura.

${ }^{40}$ Una de las leyendas más narradas en la literatura védica: RV 5.30.8, 8.14.13, MS 4.3.4, VS 19, 20, TBr. 1.7.1.7, PBr. 12.6, 8-10; 7.6.8, JBr. 2, 134, ŚBr. 12.7.3.1-4, 10-14 y 12.7.3, 1 y 4; 5.4.1.9 y ss., MBh 9.42.27-41.

${ }^{41}$ Mss. nihärà், nīhāré.
} 
En verdad, dioses y asura estaban en pendencia (...). En verdad, Indra no atrapaba a Namuci. Éste trenzó unas riendas y montó a aquel Āditya. ${ }^{42}$ [Indra] le aplacó con buenas palabras: «-Seamos amigos (sakhi).» ${ }^{43}$ [Namuci] dijo: «-Yo no te mataré.» [Indra] dijo: «-Quiero concertar contigo un trato, que no te mate ni de día ni de noche, ni con seco ni con mojado.» Justo al salir ese sol, extendió una bruma y le cortó con espuma de las aguas la cabeza; ésta en verdad le persiguió rodando, [y decía]: «-¡Eres traidor al pacto (mitra-drúh-)!,» pues maldad (pāpmán) en verdad era la cabeza de Namuci, y la maldad en verdad le perseguía rodando. La maldad, [Indra] con esto se la quitó ${ }^{44}$, la maldad se la quita uno con esto: traen amarantos ${ }^{45}$ del seno de de las aguas. Las aguas en verdad son matadoras de monstruos, ${ }^{46}$ los monstruos no cruzan las aguas para decapitar ${ }^{47}$ a los monstruos. Lo deseado es la dádiva ritual (dákșiṇā), y es con lo deseado con lo que se gana lo deseado. Pues uno mismo es la ganancia, pues a uno mismo la [cabeza] de ese [Namuci] ${ }^{48}$ lo persigue rodando. [Hay que recitar:] «Que los dioses, que se sientan delante, con Agni como guía, matadores de monstruos, nos ayuden, que ellos nos protejan, salve a ellos.»

Ante el tremendo poder del asura Namuci, que sujeta el sol con sus riendas, ${ }^{49}$ Indra se siente en inferioridad de condiciones y se ve obligado a prestar un juramento de no agresión. Pero ya plantea Indra el pacto en unos términos que le permiten matar a Namuci: las brumas del amanecer no son ni día ni noche, y la espuma no es ni seco ni mojado. Si fuera un cuento popular al uso, se esperaría que el relato, tras la as-

${ }^{42}$ Namuci se monta en el sol («aquel Āditya») como si fuera un caballo y lo doma, esto es, se hace dueño del sol. El sol, en su advocación de Vivasvant, es el último de los Āditya o hijos de Aditi, y a través de él se vinculan los mortales a los dioses; en la prosa védica el pronombre amum «aquel» se refiere al mundo celeste, por oposición a etat «esto (de aquí)», este mundo.

43 «Aliado, socio, amigo»; la traducción usual es «amigo». Está relacionado con lat. socius, de la misma raíz que sequere «seguir» (p.i.e. * sok ${ }^{w}-h_{2}-o i->$ véd. sakhāy-); el sakhi-/ socius era primitivamente el fiel seguidor de un jefe, como miembro de una fratría guerrera.

44 Apa-han, lit. «quitar de encima de un golpe» es tanto «decapitar» como «borrar, expiar» un pecado.

${ }^{45}$ Apāmārgá- (m.) amarantácea, achryanthes aspera, planta de efectos astringentes y eméticos conocida hoy como chirchitta, chichida, y muy utilizada en brujería y en el sacrificio, sobre todo como medio de purificación ritual; su nombre indica que «limpia, enjuaga» (mrj) todo lo negativo; $c f r$. MW p. 54, EWAia, vol. II, p. 326 y C. P. Khare, Indian medicinal plants. An illustrated dictionary, Berlin-Heidelberg, 2007, pp. 11-12.

${ }^{46}$ Rákșas- (n) «mal, daño, perjuicio», personificado como «demonio, monstruo» (cfr. avéstico rašah- y rāšaiien̉hè «para dañar», AV mã rakșịh «no dañes», véd. rakṣás- m. «monstruo, demonio (nocturno)».

${ }^{47}$ De nuevo, apa-han-, junto a rakșo-han- «matador de monstruos»: se puede traducir el segundo rákṣas por «daño, mal»: «los monstruos (rákșas) no cruzan las aguas para quitar de encima males».

${ }^{48}$ Es decir: mediante la celebración de un sacrificio expiatorio específico, el brahmán obtiene como ganancia la dakșina , dádiva ritual, y el fiel que encarga el sacrificio obtiene como ganancia su propia persona ( $\bar{a} t-$ man), que de otro modo continuaría siendo «perseguida» por «la de ése», la cabeza de Namuci; estas expresiones extremadamente elípticas son típicas de la prosa védica. A continuación se introducen las estrofas que deben ser declamadas en ese ritual concreto, junto con la ofrenda de amarantos, para «quitarse de encima» una culpa dada. En la prosa védica raras veces se encuentran afirmaciones de índole general, sino que se suelen referir a un ritual concreto cuya justificación teológica se está explicando en el pasaje citado.

${ }^{49}$ La imagen tiene más fuerza aún en el original, ya que raśmin- «rienda» es la metáfora usual para los «rayos» del sol. 
tuta victoria de Indra, tuviera un final feliz. Pero el hecho es que Indra ha quebrantado con astucia un pacto que él mismo ha planteado, y por ello está sujeto al público vilipendio. La acusación de la cabeza rodante es gravísima: mitradrúg asi «traicionas un pacto», esto es, cometes $d r u ́$ h. ${ }^{50}$ En el mundo indo-iranio primitivo, el que traiciona un pacto de amistad merece el peor de los castigos. El dios Mitra védico es la personificación de mitrá, el contrato, la amistad que posibilita un pacto verbal, y aparece casi siempre emparejado con Varuna, el dios de la palabra verdadera que con sus leyes mantiene el rtá. ${ }^{51}$

Tanto el recurso a la espuma como la cabeza rodante y la acusación de traición son temas antiguos, y ya se mencionan en el RV en diversas ocasiones, p. ej. RV 8.14.13: apắm phénena námuceh śíra indród avartayah | viśvā yád ájaya spŕdhah: «Con espuma de las aguas echaste a rodar, Indra, la cabeza de Namuci, cuando a todos los enemigos venciste» $\mathrm{y}$, sobre todo, RV 5.30.7cd-8:

\section{(...) átrā dāsásya námuceh síro yád ávartayo mánave gātúm ichán || 7 \| \\ yújam hí mām ákṛthā ád íd indra síro dāsásya námucer mathāyán | áśmānam cit svaryàm vártamānam prá cakríyeva ródasī marúdbhyaḥ $\|8\|$}

7. (...) Entonces fue cuando la cabeza del dāsá Namuci la hiciste rodar, deseando para Manu camino expedito;

8 «-iPar tuyo me hiciste!-» y entonces, Indra, arrancando ${ }^{52}$ la cabeza del $d \bar{a} s a$ Namuci, [la hizo rodar como] estruendosa piedra que gira, mundos cual ruedas hacia los Marut.

Nótese que aquí Namuci, al verse amenazado por Indra, le dice: «iPar tuyo me hiciste!», pero Indra le arranca o «destornilla» (vid. n. 52) la cabeza y la echa a rodar como una roca o una rueda cuesta abajo; en la versión habitual, la cabeza de Namuci persigue a Indra rodando, y acusándolo a gritos de su traición: el orden de los hechos se ha invertido. En el primer pāda de RV 5.30.8, el término que se ha vertido como «par tuyo» es yúj, lit. «pareja (del yugo), lo unido, lo juntado», menos problemático en términos legales que mitrá, que es específicamente una alianza personal y política, y desde luego, mentarle a Indra una «unión en general» es mucho menos denigrante que llamarle mitradrúh-, uno de los peores pecados para la mentalidad védica: en el contexto eulogístico de los himnos rigvédicos, tal acusación estaría fuera de lugar y el poeta maquilla así el aspecto problemático de la hazaña de Indra que, no obstante,

\footnotetext{
${ }^{50}$ En la forma que adopta la leyenda en la epopeya (MBh. 9.42.32) la cabeza llama a Indra «malvado» (pāpa) y «asesino del aliado» (mitra-han-); en el Mahābhārata el crimen de Indra contra Namuci es considerado un brahmanicidio, el peor de los crímenes, por influencia del mito de Viśvarūpa (vid. n. 35); así se enfatiza la gravedad del crimen de Indra cuando la oposición rtá : drúh ya ha quedado obsoleta.

${ }^{51}$ Sobre Mitra como personificación del contrato, vid. Meillet, A., 1907, «Le dieu indo-iranien Mitra», JA 10, pp. 143-159; para la relación con Varuṇa, cfr. P. Thieme, Mitra and Aryaman; New Haven, 1957, pp. 60ss.

${ }^{52}$ Mathāyán describe el movimiento de giro alternativo que se emplea para frotar las maderas de encender el fuego, batir la mantequilla o taladrar: casi literalmente, Indra le «destornilla» la cabeza a Namuci, en alusión al movimiento giratorio.
} 
ha de incluir en el catálogo. Indra tiene un lado amoral y oscuro que, de un modo u otro, se atenúa en el RV, mientras que la literatura brahmánica, obsesionada con la pureza ritual, lo acentúa continuamente cuando emplea mitos como este como justificación mítica para un determinado procedimiento ritual. En todo caso, hay que guardarse de entender la poderosa imagen de la cabeza de Namuci rodando tras Indra y llamándolo traidor a gritos como una figuración del remordimiento: lo temible de la cabeza rodante es que hace público el pecado de Indra, y lo convierte así en algo vergonzoso. La mancha quedará expiada mediante el adecuado procedimiento ritual, que cambia según las versiones de la leyenda que se encuentran en la literatura brahmánica. ${ }^{53}$ El pasaje paralelo $\mathrm{PBr}$. 12.6, 8-10, donde la expresiva acusación de la cabeza rodante es virrahann adruho druha iti "asesino de guerreros, has traicionado, has traicionado», acaba diciendo simplemente: apa śucam̆ hate hārivarnasya nidhanena śríyañ ca haraś copaiti tuștuvānah «Se quita la aflicción de encima (de nuevo, apa-han) quien entona el canto final del Hārivarṇa, y alcanza así gloria y alegría». Es decir, al quedar purificado del pecado cometido mediante un ritual, se obtiene śrí «gloria», en su sentido original la belleza y esplendor que parecen emanar del que disfruta del reconocimiento público, y haras, que traducimos como abstracto de $h r$ «alegrarse», ${ }^{54}$ opuesto aquí a śucam, la «aflicción» causada por el pāpmán.

\section{LO VERGONZOSO Y LO MALO}

Finalmente, la maldad inherente a todo lo vergonzoso se generaliza, y avadyá aparece en contextos que se asimilan directamente a toda amenaza que procede del exterior. Así, se documenta junto a términos de semántica más amplia, que denotan una posible amenaza así como el mal que puede originarse de ella, p.ej. duritá- «difícil; necesidad, peligro; mal proceder, pecado», duṣkrtá «lo mal hecho, mala acción, crimen». Una de las nociones centrales en el campo semántico de lo negativo es ámhhas, la «estrechez, angustia», el «paso angosto» (cfr. lat. angor, angus-tus < i.e. ${ }^{*} h_{2} e ́ n \hat{g}^{h} O s$ ). En origen, expresaba lo opuesto a la esperanza de los pueblos arios de encontrar amplios pastizales para su ganado, via libre para sus caravanas nómadas. ${ }^{55}$ Por ende, ám-

\footnotetext{
53 Por ejemplo, en ŚBr.m. 12.7.1.10 y ss. la leyenda de Namuci sirve como mito etiológico para la sautrā$m a n ̣ \bar{l}$, un ritual de purificación específico para los que no toleran el sabor del soma, bebida que debía de tener un sabor amargo. Según esa versión, Indra se ve obligado a prestar el juramento porque se siente más débil que Namuci, ya que éste le ha emborrachado con surā, un licor alcohólico, o por haber bebido soma mezclado con surā; son los Aśvin, gemelos divinos que actúan como médicos, y la diosa Sarasvatī, quienes sanan a Indra, le indican el truco de la espuma para acabar con Namuci y, al separar el soma de la surā, instauran la sautrāmaṇi. El ŚBr.m. presenta diversas variantes de la leyenda narradas fragmentariamente en lugares distintos; G. Zeller, Die Vedischen Zwillingsgötter. Untersuchungen zur Genese ihres Kultes, Wiesbaden, 1990, ha 1levado a cabo un minucioso cotejo de las mismas.

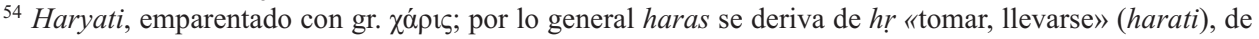
(g) $h r$ «caliente» (gharma-) con el sentido de «llama, brasa», o de $h \bar{r}$ «encolerizarse» (hrṇite).

${ }^{55}$ Cfr. también la ambigüedad semántica de dur-itá- «difícil de transitar» (opuesto a «paso expedito»), que también significa «mal transitado» > «mal proceder, crimen». La dificultad de tránsito se amplia e invierte al concepto de daño recibido.
} 
has designa el sentimiento de angustia y desvalimiento provocado por la enfermedad, las calamidades, las catástrofes naturales, y finalmente, en general, el mal externo a uno mismo; ${ }^{56}$ suele implicar, como aghá (§ 8), dolor o peligro físicos. P. ej., en RV 1.115.6 se pide protección contra ámhas y al mismo tiempo contra avadyá, para obtener así una salvaguardia tanto física como espiritual, ya que se demanda tanto de los dioses «éticos» Mitra, Varuṇa y Aditi, como de Sindhu (el río Indo) y de Tierra y Cielo, que delimitan el mundo real de los pueblos védicos:

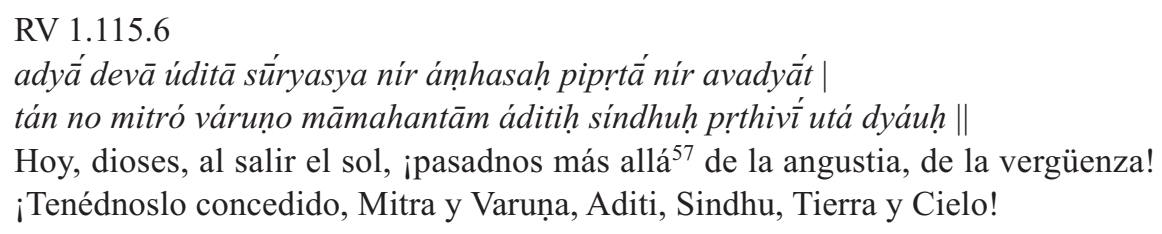

En otros pasajes, avadyá acompaña a duritá: RV 1.185.10 pātà́m avadyấd duritấd abhî́ke «(Cielo y Tierra,) guardadme de la vergüenza y del mal proceder en el momento decisivo», y RV 7.12.2 sá no rakșișad duritấd avadyád «que nos proteja del mal proceder y la vergüenza», donde duritá no se refiere a la mala conducta del orante, sino a las malas acciones que otros puedan emprender contra él; $c f r$ también RV 5.053.14ab átīyāma nidás tiráh svastíbhir hitvā́ avadyám árātīh «que lleguemos más allá ${ }^{57}$ del reproche, con bendiciones, habiendo dejado atrás vergüenza y hostilidad». En época postvédica, avadyá cae en desuso y el compuesto negativo anavadya pasa a significar tan solo «sin tacha, sin defecto (físico)»; así, en MBh se emplea casi exclusivamente referido a la belleza de las mujeres (p. ej., anavadyāingī «la de miembros sin tacha») ${ }^{58}$ los compuestos sāvadya y nir-avadya en cambio sí conservan el matiz moral (p.ej. en MBh 13.133.53 pregunta Umā a Śiva: sāvadyam kị̣ nu vai karma niravadyam tathaiva ca «¿qué acción pues es vergonzosa y cual es ciertamente no vergonzosa?»).

\section{EL VITUPERIO Y LA CULPA}

En las culturas de la vergüenza la autoestima individual depende de lo que de uno se dice: śravas, la «fama» a la que aspira todo noble védico, es un derivado de

\footnotetext{
${ }^{56}$ Vid. J. Gonda, «The Vedic concept of amhas», IIJ 1 (1957) pp. 33-60. Indra y Agni son los dioses a los que se les pide con mayor frecuencia que libren al mortal del ámhas; tras ellos, los dioses Mitra y Varuna emparejados, pero una única vez a Varuṇa solo, de donde se infiere que ésa es una función más propia de Mitra, el dios «amigo», cfr. S. N. Gajendragadkar, «Study of amhas, enas and āgas in the Rgveda», Indian Linguistics 28 (1967) p. 50.

${ }^{57}$ En védico las nociones de «pasar al otro lado, cruzar» o «llevar, guiar al otro lado» implican vencer, derrotar a un enemigo.

${ }^{58}$ Cfr. ya RV 10.68.3b spārhăh suvárṇā anavadyárūpāh «las deseables, de buen color, de belleza sin tacha», dicho de las vacas que liberan Bṛhaspati e Indra y que encarnan a las Auroras; RV 1.73.3d anavadyá pátijușteva nắri «como una esposa sin tacha, que complace a su marido».
} 
la raíz śru «oír, escuchar». Por eso, el individuo puede objetivar una infracción cometida como algo ajeno a su responsabilidad personal: lo importante es preservar la reputación y emprender las acciones rituales debidas para obtener la exculpación; de un modo u otro, solo se hace verdad aquello que se pronuncia en público. Una acusación pública de un crimen (cometido o no) es tan infamante como la propia culpa que denuncia. Ya hemos visto en 4.18.6-7 (§ 4) cómo las aguas hacen suya una «vergüenza» de Indra por el procedimiento de declararlo públicamente: el r rtá que proclaman las aguas no implica que sea mentira que Indra haya matado a su padre (o robado el soma, etc.): exculpan públicamente a Indra tomando su vergüenza sobre sí -limpiándola, por así decir-, y el hecho de hacerlo en voz alta es lo que certifica su afirmación. En el RV se pide a los dioses que las acusaciones en público contra el fiel se vuelvan en contra los acusadores, y esto con independencia de si la acusación es verdadera o falsa, ya que toda acusación, por principio, manchará la reputación:

\section{RV 5.3.7 \\ yó na ăgo abhi éno bhárāty ádhìd aghám agháśamse dadhāta | \\ jahî cikitvo abhiśastim etấm ágne yó no marcáyati dvayéna $\|$}

Al que nos impute ágas, énas, al que nos acuse con daño, daño hacedle;

golpea, sagaz Agni, este vituperio, que nos quiere malherir con su doblez.

Los vituperios y acusaciones en cuestión (aghá-śamsa-, abhi-śasti-) son proclamas hechas en público; la raíz śaṃs de la que derivan śaṃsa- y śasti significa «hablar en público de modo solemne» y está emparentada etimológicamente con el latín censeo. ${ }^{59}$ Aghá «daño» es otro término arcaico referido al mal de modo genérico, y más en concreto al daño que procede del exterior, que a veces se ha traducido también como «pecado». Bodewitz ${ }^{60}$ ha estudiado en detalle los problemas que implica: en RV denota a lo sumo «desdicha», falta de prosperidad, una situación que procede del exterior y que generalmente se debe a la acción de enemigos «malos» (aghá o aghakịt); aquí, el aghá-samsa- es que que habla mal en público de otro, en concreto el que habla mal del poeta ante su patrón. Así pues, en el RV aghá no es el mal cometido por uno mismo, sino más bien el mal que le hacen a uno, y sus resultados. En los textos posteriores se añade un nuevo matiz, la pena que causa la muerte de un ser querido. Como señala Bodewitz, ${ }^{61}$ aghá está conectado etimológicamente con gr. ő $\chi 0 \varsigma$ «pena, aflicción» y el gótico agis «miedo» $\left(<* h_{2} e^{g}{ }^{h}-e s-\right)$, agl $\left(<h_{2} e g^{h} e l o-\right)$ «desgraciado», $c f r$. ingl. ant. eg(e)le «desagradable».

En la ideología védica, lo que se puede y lo que no se puede hacer con la palabra es de suma importancia, ya que la palabra pronunciada según los ritos tiene control

${ }^{59}$ Cfr. J. L. García Ramón, 1993, «Lat. cēnsēre, got. hazjan und das idg. Präs. *kéns-e-ti (und *k̂kns-éie-ti) 'verkündigt, schätzt', Stativ *knss-eh ${ }^{-}$' verkündigt, geschätzt sein/werden'», Indogermanica et Italica. Festschrift für Helmut Rix zum 65. Geburstag, ed. G. Meiser, Innsbruck, 1993, pp. 106-130.

${ }^{60}$ H. W. Bodewitz, «Vedic aghám, evil or sin, distress or death?», IIJ 49 (2006) pp. 105-125.

${ }^{61}$ H. W. Bodewitz, loc. cit. p. 124. 
sobre los sucesos del universo. Así, Gonda ${ }^{62}$ señala que en el estilo poético védico por lo general los seres malignos o los animales peligrosos van desprovistos de epítetos, ya que los epítetos típicos suelen ir cargados de connotaciones positivas; y a su vez, destacar su carácter maligno podría resultar peligroso, ya que acrecentaría el poder de los demonios. El razonamiento también opera en la dirección inversa, e igual que en el mundo helénico las furias se convierten en Euménides («benevolentes»), el temible Rudra, que envía enfermedades con sus flechas y gobierna las tropas de la noche, está caracterizado siempre por epítetos positivos, tanto que en el hinduismo clásico se transformará en Śiva (ya p. ej. en RV 10.92.9), el «favorable». Por todo ello es tan grave faltar a la palabra dada; y por eso también, a la inversa, basta con enunciar «soy inocente» $\mathrm{o}$ «hazme inocente» en un entorno ritual adecuado, para que la culpa desaparezca. Cuando se les pide a los dioses quedar án-āgas- «libre de pecado, de culpa» se puede emplear el verbo $k r$ «hacer», el mismo que se emplea con palabras que significan «fechoría» o «pecado» en el sentido de «cometer»; y de modo muy significativo, también aparece con los verbos vac o brū «decir», ya que el modo más efectivo de quedar exculpado es una declaración verbal, p. ej.:

RV 1.123 .3

yád adyá bhāgám vibhájāsi n⿳̛̣bhya úṣo devi martyatrấ sujāte| devó no átra savitā dámūnā ánāgaso vocati sürryāya $\|$

Cuando hoy repartas a los hombres su porción, diosa Aurora, bien nacida entre los mortales, que el dios Savitar, señor de la casa, nos declare entonces sin culpa (ánāgaso vocati) ante el Sol.

En los textos rituales se considera que el agnihotra, libación realizada al amanecer y al atardecer, limpia del mal (pāpmán), del mismo modo que el sol al amanecer (Savitar) se desprende de la oscuridad de la noche, que viene a representar lo impuro. ${ }^{63}$

En el brahmanismo posterior una confesión pública (khyāpana) suele bastar para aliviar las consecuencias del delito, siempre que el infractor lleve a cabo un ritual expiatorio adecuado, ideología que pervive en las leyes de Manu (MDhŚ 11.227-228):

\section{khyāpanenānutāpena tapasādhyayanena ca $\mid$}

pāpakrn mucyate pāpāt tathā dānena cāpadi || $227 \|$

yathā yathā naro 'dharmam svayam kṛtvānubhāsate |

tathā tathā tvacevāhis tenädharmena mucyate || $228 \|$

227. Mediante confesión, contrición, ascesis y recitación de los Vedas, el pecador queda libre del pecado, ${ }^{64}$ y por generosidad, si no hay otra vía.

62 J. Gonda, 1959, Epithets in the Rgveda, 'S-Gravenhage, pp. 130-138.

${ }^{63} \mathrm{H}$. W. Bodewitz, The daily evening and morning offering (Agnihotra) according to the Brähmanas, Leiden, E. J. Brill, 1976, p. 153.

${ }^{64}$ Lit.: «el que ha hecho mal (pāpa-krtt) queda libre del mal (pāpa)». Mucyate «ser liberado» se emplea también al hablar de la liberación de los lazos de Varuna. 
228. En cuanto un hombre, tras infringir por sí mismo la ley, lo declara, entonces, como una serpiente de su piel, queda libre de su infracción. ${ }^{65}$

En el brahmanismo, la tradición es clara al respecto: un delito confesado públicamente implica un castigo menor; ¿porqué tiene tal poder la mera expresión verbal de una fechoría? Para el SBr.k. 1.5.17, un pecado confesado se vuelve menor, ya que «se vuelve real» (satyam bhavati). Es decir, mientras un pecado no se expresa verbalmente viene a ser un peligro en el aire, un pāpmán que puede recaer sobre cualquiera. Confesarlo equivale no tanto a hacerse responsable personal de un pecado, como dar entidad definida verbalmente a un mal que solo entonces es susceptible de eliminarse mediante la preceptiva expiación; en el brahmanismo posterior bastará con recitar unos mantra adecuados a cada infracción justo tras cometerla, y con esta prāyaścitti o expiación se considera que la infracción no ha tenido lugar. ${ }^{66}$ Hacer que algo sea verdad es un «acto de verdad», saccakiriyā en pāli (sánscrito *satyakriyā o satyavādya «declaración de verdad»), un tipo de juramento bien documentado en la India budista, pero que hunde sus raíces en la ideología védica: ${ }^{67}$ es una declaración verbal que convierte en real (satya) lo que se dice, por el hecho mismo de decirlo. En el pensamiento védico primitivo el lugar de satya lo ocupaba, con mayor propiedad, rtá. ${ }^{68}$ Lo importante de esta formulación es que se basa tan sólo en la mera autoridad de quien emite la satyakriya, por medio de su «palabra verdadera». Sin embargo, en pocas ocasiones podemos encontrar una satyakriyā védica que tenga un carácter exculpatorio; obsérvese RV 1.185.8 y 10:
devā́n vā yác cakrmā́ kác cid ắgah sákhāyam vā sádam ỉj jā́spatim vā |

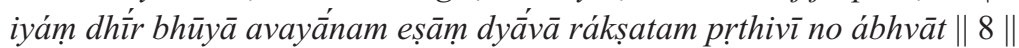
8. Sea contra los dioses cualquier ág gas que hayamos cometido, sea contra un ami- go $\left(s a k h i^{43}\right)$ de siempre, sea contra el señor de la familia, sirva de disculpa esta oración ante ellos; Cielo y Tierra, guardadnos del abismo.

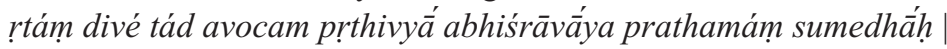

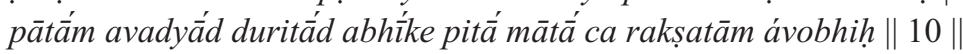 10. Esta verdad (rtá) en el Cielo la he dicho, en la Tierra, para ser escuchado prime- ro como sabio; protegedme de lo vergonzoso (avadyá) y del mal proceder (duritá) a la vez; padre y madre, guardadme con vuestras ayudas.

${ }^{65}$ Idéntica imagen en ŚBr.m. 2.3.1.6.

${ }^{66}$ J. Gonda, Mantra interpretation in the Śatapatha-Brāhmaṇa, Leiden, 1988, p. 159: «A clear instance of the power believed to be inherent in a recited confession of faith, or act of truth or praise, scarcely ditinct of a confession of sin, because it also is assumed to make good and harmless the dangerous consequences of $\sin . »$

${ }^{67}$ W. Norman Brown, «Duty as truth in ancient India», Proceedings of the American Philosophical Society, 116-3 (1972) pp.252-268 y esp. G. Thompson, «On truth acts in Vedic», IIJ 41 (1998) pp. 125-153; sobre los posibles orígenes indoeuropeos de la fórmula encabezada por «verdad», C. Watkins, «Is tre fir flathemon: marginalia to Audacht Morainn», Ériu 30 (1979) pp. 181-198 e idem, How to kill a dragon in Indoeuropean, Oxford, 1995, pp. 85ss.

${ }^{68}$ Lüders, op. cit., pp. 486ss. 
La oración está dirigida al padre Cielo y a la madre Tierra, antiguos dioses de raigambre indoeuropea. En 10 se lleva a cabo la manifestación de ritá, que convierte la mera enunciación de posibles pecados de 8 en una exculpación «de verdad», verificada. Finalmente, se pide protección contra lo malo que pueda producirse en lo sucesivo: se reza para evitar que las consecuencias nefastas de actos vergonzosos o mal encaminados (avadyá, duritá) recaigan sobre uno, aun sin saber de qué pecados se trata. Así, el creyente védico se desliga de la responsabilidad de sus actos; una situación de impureza ritual a la que se llega por casualidad o ignorancia puede tener los mismos efectos que un crimen premeditado, y da lugar a idéntica necesidad de expiación para apartar las consecuencias nefastas. 